\title{
Conversation and convention: Enduring influences on name choice for common objects
}

\author{
BARBARA C. MALT \\ Lehigh University, Bethlehem, Pennsylvania \\ and \\ STEVEN A. SLOMAN \\ Brown University, Providence, Rhode Island
}

\begin{abstract}
The name chosen for an object is influenced by both short-term history (e.g., speaker-addressee pacts) and long-term history (e.g., the language's naming pattern for the domain). But these influences must somehow be linked. We propose that names adopted through speaker-addressee collaboration have influences that carry beyond the original context. To test this hypothesis, we adapted the standard referential communication task. The first director of each matching session was a confederate who introduced one of two possible names for each object. The director role then rotated to naive participants. The participants later rated name preference for the introduced and alternative names for each object. They also rated object typicality or similarity to each named category. The name that was initially introduced influenced later name use and preference, even for participants who had not heard the name from the original director. Typicality and similarity showed lesser effects from the names originally introduced. Name associations built in one context appear to influence retrieval and use of names in other contexts, but they have reduced impact on nonlinguistic object knowledge. These results support the notion that stable conventions for object names within a linguistic community may arise from local interactions, and they demonstrate how different populations of speakers may come to have a shared understanding of objects' nonlinguistic properties but different naming patterns.
\end{abstract}

How do people choose names to refer to common objects such as pens and cups? Contributing to the choice are the objects' physical features, their current function, and possibly inferences about their intended use or origin. Views of categorization as applied to the problem of object naming have focused on these sources of constraint (e.g., Bloom, 1996; Keil, 1989; Kemler Nelson, 1999; Rips, 1989). We have argued, though, that name choice is not fully determined by knowledge or beliefs about the object per se; it is also sensitive to influences such as a language's history and the particular history of a speaker and addressee (Malt, Sloman, \& Gennari, 2003a, 2003b; Malt, Sloman, Gennari, Shi, \& Wang, 1999). The name a person uses for an entity is influenced by the set of names his or her language makes available for that domain and the pattern of naming that the language has evolved for objects in that domain, as well as by the goals

This work was supported by NIMH Grant MH51271 to B.C.M. and S.A.S. and an American Philosophical Society sabbatical fellowship to B.C.M. We thank Boaz Keysar, Heather Bortfeld, Simon Garrod, and several anonymous reviewers for helpful comments on a previous draft of this article; Bonnie Green, Kevin Reilly, Kristine Schuster, and Cecilia Stanton-Stevenson for assistance in data collection and analysis; and confederates Brianna Eiter, Kristy Kulik, Brenden Gegwich, Louisa Weiss, and Erin Liebman for excellent acting. Correspondence relating to this article may be sent to B. C. Malt, Department of Psychology, 17 Memorial Drive East, Lehigh University, Bethlehem, PA 18015 (e-mail: barbara.malt@lehigh.edu). of the particular communication and other aspects of the common ground of the speaker and addressee.

Evidence for the importance of short-term goals and speaker-addressee history comes from studies of reference demonstrating the role of collaboration between a speaker and an addressee in establishing and carrying forward names in a conversation (e.g., Brennan \& Clark, 1996; Carroll, 1980; Clark \& Wilkes-Gibbs, 1986; Garrod \& Anderson, 1987; Krauss \& Weinheimer, 1966; Markman \& Makin, 1998). Evidence for longer term historical influences on naming choices was provided by Malt et al. (1999), who found that naming patterns for a set of 60 common artifacts in the same neutral context diverged substantially for speakers of English, Spanish, and Chinese. For instance, the 16 objects called bottle in English were distributed across seven different linguistic categories in Spanish. The Chinese name applied to the 19 objects called jar in English also was used for 13 objects called bottle in English and 8 called container; at the same time, other objects called bottle or container in English had different Chinese names. These naming differences occurred even though physical, functional, and overall similarity judgments were much the same across speakers of the different languages. Patterns of naming appear to emerge over the history of a language and are driven by more than perceived or inferred properties of the objects (see also Hock \& Joseph, 1996; Malt et al., 2003b; Singleton, 2000). 
Short- and long-term historical influences must somehow be linked: Names introduced or adopted for an object by one person or a small number of people must spread beyond the initial users to a larger linguistic community if the names are to become conventional for all members of the group. How do short-term naming choices evolve into stable linguistic conventions? One possibility is that conventions emerge when members of a community accumulate common knowledge of how other community members would name an entity; that is, when all members of a community not only know a particular name but believe the name to be shared by the other members and believe that other members likewise believe it to be shared (Clark, 1998; Lewis, 1969).

Garrod and Doherty (1994) have suggested, however, that local processes may lead to global conventions without the involvement of mutual knowledge. They propose that individuals follow an "output-input coordination principle" (Garrod \& Anderson, 1987) whereby speakers tend to match the lexical, semantic, and pragmatic options used to interpret the last relevant utterance from their conversational partner (see also Levelt \& Kelter, 1982; Pickering \& Garrod, in press). Dyads thus reach a coordination "equilibrium." Once a precedent is set for a speaker through this coordination process, he or she will draw on that precedent in subsequent interactions with other partners. Across subsequent pairwise interactions, the output-input coordination principle will lead to increased likelihood of use of the precedent by larger and larger numbers of community members and will ultimately result in a shared convention. The convention may be appreciated as such by members of the community, but shared knowledge of its existence is not a causal factor in its emergence.

Garrod and Doherty (1994) tested their proposal using a variant of the standard referential communication task (e.g., Clark \& Wilkes-Gibbs, 1986; Krauss \& Glucksberg, 1969; Krauss \& Weinheimer, 1966) in which two people, each having the same set of pictures, must arrange their pictures in matching order without seeing each other's work. One serves as director, providing instructions to the other (the matcher). The data of interest are how the two communicate about the pictures. In Garrod and Doherty's version of this task, pairs repeatedly played a game in which each player tried to move through a maze with the assistance of his or her partner. Participants either interacted with the same partner for 10 games or else with a different partner each time drawn (without replacement) from a community of 10 players. Garrod and Doherty found that speakers in the community group rapidly converged on one of four possible schemes to refer to the mazes. In contrast, the isolated pairs used a greater mix of schemes and did not show convergence across the set of games. These results are consistent with the notion that linguistic conventions may emerge from local interactions.

The possibility that local interactions may yield community conventions is further supported by computer simulations carried out by Barr (in press). Agents from a pop- ulation of 1,000 played a signaling game with a series of partners chosen from the same population. Each agent interacted primarily with only a small subset of the possible partners. The goal of the game was to communicate a series of four meanings using one of a set of four lexical forms for each. There were 24 possible mappings of forms onto meanings, and each agent began with a randomly selected mapping. On each iteration of the game, the mappings held by a pair of agents were compared and, if they did not match, adjusted using an algorithm that took into account other recent successes and failures of that mapping. In accord with Garrod and Doherty's (1994) findings, the population of agents rapidly converged on a shared set of mappings under most conditions.

As Garrod and Doherty (1994) note, their task strains the resources of conventional language by requiring participants to devise ways of distinguishing among maze positions in a game they had never played before. The researchers suggest that language change tends to come about in just such situations - those in which novel cultural or technological phenomena are experienced and need to be talked about. But the sort of naming their task required was particularly complex, with the conventions that evolved consisting of multiword phrases that identified locations in two-dimensional arrays in a particular way. Once a speaker had successfully communicated using one way of specifying a location, the gain in efficiency from reusing the same strategy may have been particularly high.

Many linguistic conventions are much simpler in nature and concern only a noun or noun phrase-for instance, the conventions constituting dialect differences in naming within a language (e.g., grinder vs. hoagie vs. submarine sandwich or elevator vs. lift in English) and the naming conventions noted earlier that differ across speakers of different languages (e.g., English speakers may call each of two household containers a bottle, whereas Spanish speakers call one botella and the other frasco). Will the influence of a precedent extend beyond the dyad first establishing it when basic-level or other simple names for common objects are the target? Although Barr's (in press) simulations demonstrate that dyadic interactions can lead to broader conventions for simple lexical expressions in principle, the simulations cannot tell us whether in practice the processes engaged in by humans in normal conversational interactions will result in such conventions. We suggest that even when basic-level or other simple names are being selected for familiar household objects, speakers will draw on precedents, because naming experiences will tend to alter the strength of association of possible names to objects. When later choosing a name for any of the same objects, these altered association strengths will influence what name is likely to be retrieved and proposed, and hence adopted, with either the same or a new conversational partner. Indeed, Sloman, Harrison, and Malt (2002) found that in a forced choice task a prior naming experience tended to bias selection of a name for an ambiguous object on a later trial, and Brennan and Clark (1996) found that in succeeding 
rounds of a matching task speakers tended to reuse names for pictures even when the name was more specific than was needed for the current trial. Each subsequent adoption will, itself, further strengthen a preference for one name over another, and the influence of one naming experience may thus be carried forward into the next and beyond.

We suggest, therefore, that conventions across a community may arise from local coordination in the case of simple object names, just as Garrod and Doherty (1994) have found in the case of more complex linguistic expressions. In the two experiments presented here, we tested the hypothesis that basic-level or other simple (modifier + noun) names for ordinary household objects introduced into a conversation will influence subsequent name use and name preference, including when a speaker is interacting with a conversational partner other than the one with whom the precedent was established.

To test this hypothesis, we created a new variant of the referential communication task. In our version, the objects to be put into matching order were pretested to ensure that two different names were acceptable for each at the same level of specificity, outside of any particular context. The first director of each experimental session was a confederate of the researchers and introduced one of the two possible names for each object in his or her directions to the matcher. In Experiment 1, the original director completed three rounds of matching (three trials) with the first matcher. The matcher then became director, and a new participant became matcher for three trials; finally, this second matcher became director to a new (to this participant) partner, the first director. In Experiment 2, after the original director and matcher completed three rounds of matching, they switched roles for three more trials. After completing the matching tasks, the participants rated name preference for both the originally introduced name and the alternative name for each object. They also rated typicality (in Experiment 1) or similarity (in Experiment 2) for each object in relation to each named category, in order to provide a comparison of linguistic performance with a judgment that did not primarily relate to reference.

Corresponding to our hypothesis, we made two central predictions: (1) Evidence of the originally introduced name would be seen in the speech of the third director in the third block of trials in Experiment 1, even though this director had had no previous contact with the person who originally used the names and had no way of knowing what names that person had used. (2) When both possible names are brought to participants' attention, name preference (after having been exposed to one set or the other in the matching task) will favor the exposed set, even in a context concerning communication with a new audience. That is, people will feel that the name they have been exposed to is a better choice for future labeling of the object, reflecting the greater strength of association that they now have for that name with the object. This preference should extend to the third director as well as to the second-again, despite the fact that this director has had no contact with the person who originally introduced the name.

If shifts in name use and name preference come from altered association strengths of names to objects, and hence from alterations in retrievability of the names from memory, the names learned are not likely to alter understanding of nonlinguistic properties of the objects. Therefore, an additional prediction is that shifts in name use and preference will not be paralleled in typicality or similarity ratings, which require evaluation and comparison of properties of objects other than just their names. This finding would be consistent with our previous observation of a shared perceived similarity of objects by speakers of languages that have different naming patterns for them (Malt et al., 1999) and would demonstrate how such dissociations of naming and conceptualization may come about.

\section{Stimulus Selection}

Forty common objects were photographed. The objects were chosen as likely to have two acceptable names. Names were tested in two ways: First, in a production task, 25 Lehigh undergraduates saw each photograph on a computer screen and typed in whatever name they thought they would call the object in ordinary conversation. These names were tallied to determine the most consistently produced names. Second, the objects were presented with the selected names to a new group of 14 Lehigh undergraduates who rated each picture using a 0 -to-7 scale on how typical the object was of its selected categories.

Fourteen objects were chosen that had two balanced names, as indicated by mean typicality differences of no greater than 1.0. The objects were a booklet/pamphlet, bucket/pail, bottle/jar, pen/marker, disk holder/case, lotion bottle/tube, coffee cup/thermos, water bottle/juice box, trash can/wastebasket, tube/container, bowl/dish, apparatus/flask, dish/platter, and fleece/fleece jacket. The two names used for each object were those given in this list. The names were divided into two sets, each containing one name for each object. One set ("Set A" hereafter) included names that were slightly less preferred according to the typicality ratings and original production frequencies, and the other ("Set B") included the slightly more preferred names. The mean typicality ratings were 5.23 and 5.62 for Sets A and B, respectively; the mean production frequencies were 5.57 and 11.78 , respectively.

\section{EXPERIMENT 1}

This experiment tested both central predictions and the secondary one, using the three-phase version of the referential communication task in which the matching task was followed by name preference and typicality ratings.

\section{Method}

Seventy-two Lehigh undergraduates participated for course credit. Stimuli were two identical sets of 14 cards, each containing the photo of one of the objects selected in the pretests. When each pair 
of undergraduate participants arrived, along with the undergraduate confederate, the experimenter explained that the experiment would investigate how pairs of people worked with each other in carrying out a task, and she briefly explained the task. The experimenter then asked the confederate to serve as the first director, one naive participant to serve as the first matcher, and the other to wait in a nearby room.

The director and matcher were seated at a table with an opaque barrier between them. Unseen by the matcher, on the director's side of the table was a "cheat sheet" with a picture of each object and the name to be used for it. The experimenter shuffled the cards, laid out one set in two rows of seven in front of the director, and gave the other set to the matcher. The pair then completed three trials of the matching task, with the cards shuffled between trials. For each trial, the director gave instructions to the matcher until their card orders matched. In the first trial, the director attempted to use the designated name twice in a natural way when talking about each object for the first time. The repetition was usually in the form of an elaboration on the nature of the object (e.g., "The top left item is a platter, a clear glass platter") or a request for confirmation that the matcher had identified the object (e.g., "The top left item is the glass platter. Do you see the platter?"). At the beginning of each trial, the experimenter activated a tape recorder that recorded the entire session.

After the third trial was completed, the director slid the cheat sheet under notebooks on the table and removed it while moving to the waiting room. The matcher then moved to the director's place and the waiting participant was called in to serve as matcher. This pair completed three matching trials in the same manner, except that the director had no instruction about how to name the objects. In the final block of three trials, the second matcher became director, and the original director became the matcher. (The third matcher's responses were virtually always simple confirmations such as "yes" and "yup, got it" and so did not elicit any referring expressions from the third director beyond what he or she spontaneously produced for each object.)

For half of the experimental sessions, Set A names were introduced in the first trial of the first block. For the other half, Set B names were introduced.

After the matching task, the participants completed a questionnaire on name preferences for the objects. The instructions asked them to imagine that they were writing copy for a catalog selling the objects they had just seen, and to judge which name would be the bestfitting or most natural for describing the object in the catalog to customers. This instruction was intended to induce them to consider how best to communicate with a broad audience that had not been part of any previous discussion of the objects. The objects were presented as a smaller version of the picture used in the matching task, and each was shown with the two possible names next to it. The participants rated the goodness of each name on a 1-to-7 scale.

The participants then rated the typicality of each object with respect to named categories. The objects were again presented as smaller versions of the pictures used earlier. Each object was rated once with respect to the category labeled by the introduced name and once with respect to the alternative name. Ratings were again on a 1-to-7 scale.

Two versions of each rating sheet were used, varying order of objects and order of names. The confederate participated in both rating tasks in order not to expose his/her status as confederate; these ratings were later discarded.

\section{Results and Discussion}

Sessions were transcribed and object references by the director were coded as matching a Set A name, a Set B name, or neither. A term was considered to match if the head nouns of the referring expressions were identical.
Mean name preference and typicality ratings were calculated. Degrees of freedom for subject analyses reported below vary slightly as a result of occasional missing data caused by failure of a participant to fill out one form or another.

Table 1 gives the proportion of names from each word set used on the last matching trial of the third block of the experiment by the third director-the participant who had never heard names from the original director. The table shows that name use at this final point was influenced by the names introduced by the first director on the first trial of the first block. Set A names were used more if they had been introduced in the first trial than if Set B names had been, and Set B names were used more if they had been introduced. The interaction was significant by subjects $\left[F(1,34)=52.20, M S_{\mathrm{e}}=0.014, p<\right.$ $.0001]$ and by items $\left[F(1,26)=43.52, M S_{\mathrm{e}}=0.013, p<\right.$ $.0001]$. (The overall preference for Set B names reflects their higher preexperimental typicality and production frequency.)

Table 2 gives the mean name preference ratings for the second director, who had been exposed to names by the original director, and for the third director, who had not. Both directors showed an influence of the names used by the original director in the first trial of the first block. Set A names were liked better when they had been introduced originally than when Set B names had been, and vice versa for Set $B$ names. The interaction was significant for the second director both by subjects $[F(1,33)=$ $\left.55.22, M S_{\mathrm{e}}=0.313, p<.0001\right]$ and by items $[F(1,26)=$ $\left.6.49, M S_{\mathrm{e}}=0.12, p<.02\right]$. Likewise, the interaction was also significant for the third director by subjects $\left[F(1,32)=23.47, M S_{\mathrm{e}}=0.162, p<.0001\right]$ as well as by items $\left[F(1,26)=10.72, M S_{\mathrm{e}}=0.09, p<.005\right]$.

Table 3 gives the mean typicality ratings for the second and third directors. In comparison with the first two measures, typicality showed a reduced effect of the introduced set of words. For the second director, the pattern of interaction of word set with group was found by subjects $\left[F(1,34)=27.29, M S_{\mathrm{e}}=0.301, p<.0001\right]$ and by items $\left[F(1,26)=36.88, M S_{\mathrm{e}}=0.17, p<.0001\right]$, but it was not numerically as strong as for the preference ratings for the second director. To more directly compare the typicality and name preference results, we calculated effect sizes for each measure by comparing the mean ratings for names that were introduced in the first block to the means for those that were not. Cohen's $d$ (Cohen,

Table 1

Proportion of Names Used From Each Word Set in the Third Trial of the Third Block by the Third Director, Experiment 1

\begin{tabular}{ccc}
\hline & Set A Names & Set B Names \\
\hline Group 1 & .34 & .36 \\
Group 2 & .15 & .57 \\
\hline
\end{tabular}

Note-Proportions do not add up to 1.0 because participants could use a name not in either set. For Group 1, Set A names were introduced in the first block, whereas for Group 2, Set B names were introduced in the first block. 
Table 2

Mean Preference Ratings, Experiment 1

\begin{tabular}{cccccc}
\hline & \multicolumn{2}{c}{ Second Director } & & \multicolumn{2}{c}{ Third Director } \\
\cline { 2 - 3 } \cline { 5 - 6 } & Set A & Set B & & Set A & Set B \\
& Names & Names & & Names & Names \\
\hline Group 1 & 5.36 & 5.20 & & 4.88 & 5.23 \\
Group 2 & 4.43 & 6.26 & & 4.50 & 5.80 \\
\hline
\end{tabular}

Note-For Group 1, Set A names were introduced in the first block, whereas for Group 2, Set B names were introduced in the first block.

1988) was greater for the name preference effect, 1.27 , than it was for the typicality effect, 0.942 . For the third director, Set A names were actually slightly lower in typicality when they had been the introduced names. The interaction of word set with group was not significant by subjects $\left[F(1,32)=0.76, M S_{\mathrm{e}}=0.21, p>.30\right]$ nor by items $\left[F(1,26)=1.12, M S_{\mathrm{e}}=0.12, p>.30\right]$. Again, Cohen's $d$ showed a smaller effect size for typicality ratings, 0.156 , than for preference ratings, 0.739 . An analysis of variance (ANOVA) with rating task (typicality vs. name preference) as a factor also showed the differing impacts of naming experience on the two types of ratings: Task interacted significantly with group (Set A introduced in the first trial of the first block vs. Set B introduced) and word set (Set A vs. Set B) by subjects $[F(1,196)=8.39$, $\left.M S_{\mathrm{e}}=0.24, p<.005\right]$ and by items $[F(1,182)=12.26$, $\left.M S_{\mathrm{e}}=0.14, p<.001\right]$. This task effect was similar for both directors, with nonsignificant interactions with director $[F(1,196)=0.06$ by subjects; $F(1,182)=0.13$ by items].

The results were thus consistent with the two central predictions. The name use results show that a bias toward use of one name over another carries beyond a precedent established between two speakers to influence name choice by a speaker who has not participated in the original agreement. ${ }^{1}$ The name preference results show that exposure to names increases the judged appropriateness of the names for future communication in comparison with other possible names. This effect likewise is not limited to a person who has heard the names from the original introducer but also occurs for a person to whom names have been passed through an intermediary. Furthermore, it holds with respect to a context (catalog copy) that is quite separate from that of the matching task in which the names were originally used. These outcomes support the proposal that conventions across communities may arise from local coordination for simple

Table 3

Mean Typicality Ratings, Experiment 1

\begin{tabular}{cccccc}
\hline & \multicolumn{2}{c}{ Second Director } & & \multicolumn{2}{c}{ Third Director } \\
\cline { 2 - 3 } \cline { 5 - 6 } & Set A & Set B & & Set A & Set B \\
& Names & Names & & Names & Names \\
\hline Group 1 & 5.39 & 5.16 & & 4.80 & 5.14 \\
Group 2 & 4.96 & 6.09 & & 5.19 & 5.72 \\
\hline
\end{tabular}

Note-For Group 1, Set A names were introduced in the first block, whereas for Group 2, Set B names were introduced in the first block. object names just as they do for more complex linguistic expressions, as found by Garrod and Doherty (1994).

Because typicality judgments are most centrally about the relation of an object to a prototype, they should be less susceptible to an influence of naming experience than the other measures, if the influence of the naming experience is primarily on the association of names with the objects. The greater stability of the typicality judgments compared with the name use and preference data supports this suggestion and is in agreement with our expectation and with previous data showing equivalent similarity judgments for speakers of English, Spanish, and Chinese despite the different naming patterns in the various languages (Malt et al., 1999). This result, in conjunction with the first, demonstrates how a dissociation between naming patterns and conceptualization of objects may come about.

\section{EXPERIMENT 2}

The main purpose of this experiment was to replicate and extend the findings from the two rating tasks of Experiment 1 . We repeated the name preference rating task but examined judgments about the nonlinguistic properties of the objects in a different way. Although the typicality ratings showed a reduced influence of the introduced name set, a significant interaction of word set with group was still present for the second director. It had been our expectation that to make typicality judgments, participants would mentally compare objects to prototypes associated with the name. Such a comparison should be relatively unaffected by changes in strength of association of the name to objects. However, familiarity and frequency of exposure sometimes influence typicality ratings (e.g., Ashcraft, 1978; Malt \& Smith, 1982), and perhaps the exposure to one set of names in conjunction with the objects made those objects temporarily seem more familiar or frequent as members of the exposed name category than as members of the alternative one, leading to a linguistic influence on the judgment we had expected to be nonlinguistic. We therefore tested another form of judgment that puts even more weight on objects' nonlinguistic properties - similarity ratings - to see if this new judgment would show less influence of the naming experience than did use and preference for the names themselves.

To simplify the procedure, we shortened the referential communication task to two blocks. The confederate served as first director, as before, and introduced one set of names or the alternatives. After three trials of matching, the previous matcher then became the director, and the confederate became the matcher. If precedents are drawn on in making naming choices, names established between a pair should continue to be used when the roles are switched, and indeed Brennan and Clark (1996) have found this pattern. However, their study did not use cases where two possible names at the same level of abstraction have been determined to be acceptable for each ob- 
ject. Our experiment allowed us to test the use of precedents when speakers have two alternative names at the same level of abstraction available to label the same objects. We expected to find a strong effect of the word set introduced in the first block on the names used by the new director in the second block.

\section{Method}

Pretest. Twenty-four Lehigh undergraduates generated properties of typical examples of the named categories, following standard instructions to list all the properties that are in general true of the object named and to avoid free associations (e.g., Malt \& Smith, 1984). Half received the Set A names, the other half, the Set B names. The features were tallied to determine the most frequent ones. Those produced by at least a third of the participants were used to construct a fixed reference point for the similarity task.

Main experiment. Twenty-five Lehigh undergraduates participated in two blocks of three matching trials apiece. In Block 1, the confederate acted as director and introduced names from Set A or Set B, as in Experiment 1. In Block 2, they switched roles so that the matcher became director to the confederate.

Following the matching trials, the participants made the same name preference judgments as in Experiment 1. Then they made the similarity judgments. For each judgment, the instructions told the participants to picture a typical member of the named category and listed attributes as determined by the pretest. For instance, for the name bucket, the instructions read, "Picture in your mind a standard, ordinary bucket. It usually holds water or other things, has a handle, and is plastic." The participants were then asked to look at the to-be-judged object (the bucket/pail from the matching task, shown as before as a smaller version of the picture used in the matching task) and rate how much it was like the standard, ordinary bucket. To encourage them to consider the standard item as described, without distorting it by thinking of attributes of the to-bejudged object, the participants were given a sheet of paper to use to first expose only the sentences concerning the standard. They were instructed to slide the sheet down to look at the to-be-judged object only after picturing the standard item. The two judgments for each object were separated by at least four intervening objects.

\section{Results and Discussion}

Table 4 gives the proportion of names from each word set used on the last matching trial of the second block by the second director. The expected pattern is present, with participants to whom Set A names were introduced using those names more than Set B names, and vice versa. The interaction was significant by subjects $[F(1,23)=$ $\left.174.11, M S_{\mathrm{e}}=0.017, p<.0001\right]$ and by items $[F(1,26)=$ $\left.116.18, M S_{\mathrm{e}}=0.03, p<.0001\right]$.

Table 5 gives the mean name preference ratings for the second director. These ratings were also strongly affected by the set of names introduced, with Set A names preferred over Set B names when Set A names had been introduced, and vice versa for Set B names. The interaction was significant by subjects $[F(1,22)=20.76$, $\left.M S_{\mathrm{e}}=0.384, p<.0002\right]$ and by items $[F(1,26)=71.90$, $\left.M S_{\mathrm{e}}=0.13, p<.0001\right]$.

Table 6 gives the mean similarity ratings for the second director. In contrast to the strong effects of the introduced names on name use and preference, and even though the director whose responses are of interest here had been exposed to the names directly from the confederate without any intervening block, the influence of
Table 4

Proportion of Names Used From Each Word Set in the Third Trial of the Second Block by the Second Director, Experiment 2

\begin{tabular}{ccc}
\hline & Set A Names & Set B Names \\
\hline Group 1 & .55 & .21 \\
Group 2 & .11 & .74
\end{tabular}

Note-Proportions do not add up to 1.0 because participants could use a name not in either set. For Group 1, Set A names were introduced in the first block, whereas for Group 2, Set B names were introduced in the first block.

introduced names on similarity ratings was relatively weak (Cohen's $d=1.05$ for name preference, compared with 0.368 for similarity). Set B items did show increased similarity judgments when they had been introduced, but Set A items did not. The overall interaction fell slightly short of significance by subjects $\left[F(1,23)=3.89, M S_{\mathrm{e}}=\right.$ $0.186, p=.06]$, although it was significant by items $\left[F(1,26)=5.30, M S_{\mathrm{e}}=0.15, p<.03\right]$. The weaker effect on similarity as opposed to preference ratings - which were made on the same scale in a similar question format - is also supported by a combined ANOVA showing a significant interaction of task (similarity vs. preference judgment) with group (Set A introduced in the first trial of the first block vs. Set B introduced) and word set (A vs. B) [by subjects, $F(1,66)=6.0, M S_{\mathrm{e}}=0.31, p<.02$; by items, $\left.F(1,78)=6.49, M S_{\mathrm{e}}=0.36, p<.02\right]$.

The name use result in this experiment is predicted by the notion that conversational partners draw on precedents in name selection. It extends the findings of Brennan and Clark (1996) by showing that precedents influence name choice when two names at the same level of abstraction are available as choices. The preference results, more importantly, replicate the Experiment 1 finding that introduction of a name by one person cannot only cause it to be used by another person but also make it the preferred name for communicating with a new audience in a different context. This outcome again supports the notion that local processes may lead to community conventions for simple object names.

The similarity finding provides added evidence that shifts in name use and name preference are at least partially independent of nonlinguistic understanding of the objects. More influence of naming on similarity was obtained here than in Malt et al. (1999). The difference may be that in that study, similarity judgments were between pictured objects, with no mention of names. In the present task, judgments were instead based on similarity to a named category. Responses may have been influenced by the exposure to one set of names despite our attempt to induce

Table 5

Mean Name Preference Ratings, Experiment 2

\begin{tabular}{ccc}
\hline & Set A Names & Set B Names \\
\hline Group 1 & 5.33 & 5.22 \\
Group 2 & 4.39 & 5.90 \\
\hline
\end{tabular}

Note-For Group 1, Set A names were introduced in the first block, whereas for Group 2, Set B names were introduced in the first block. 
Table 6

Mean Similarity Ratings, Experiment 2

\begin{tabular}{ccc}
\hline & Set A Names & Set B Names \\
\hline Group 1 & 4.95 & 4.76 \\
Group 2 & 5.02 & 5.31 \\
\hline
\end{tabular}

Note-For Group 1, Set A names were introduced in the first block, whereas for Group 2, Set B names were introduced in the first block.

the participants to focus only on nonlinguistic properties. In any case, the present results further illustrate how shifts in naming brought about by strengthening the association with an object of one name over another may be dissociated from nonlinguistic understanding of the objects.

\section{GENERAL DISCUSSION}

The results of these two experiments demonstrate that historical influences on naming patterns for common objects are not limited to the history between a speaker and an addressee, a topic that has been the focus of mutual knowledge/conversational pact accounts of name choices (e.g., Brennan \& Clark, 1996; Clark, 1998; Clark \& Marshall, 1981). Names introduced into a conversation have a scope of influence that goes beyond the initial conversational partners: They influence subsequent name use with new partners, as well as judgments of the preferred name for future communications about the objects, even when those judgments concern communicating with an audience that has not shared the previous naming experience.

Our finding on name use is compatible with a finding by Brennan and Clark (1996), who manipulated the contrast set present with each picture on different trials of a matching game and observed whether carryover of very specific names occurred when the current context would have permitted use of a less specific name. In one condition, their director either continued with the same matcher or was paired with a new matcher after the first block of trials. Brennan and Clark found greater carryover of the specific terms when the matcher remained the same, and on this basis they argued for the importance of conceptual pacts between speakers and addressees - that is, of agreement between the partners about how to characterize the object - in promoting carryover (see also Metzing \& Brennan, 2003; cf. Barr \& Keysar, 2002). ${ }^{2}$ However, the fact that they did find some retention of terms even with a new matcher is also consistent with our finding.

Although their findings are compatible with ours, Brennan and Clark's (1996) paradigm focused on naming at different levels of specificity, and so is less relevant to the real-world analogue of interest here, in which different patterns of name use at the same level of abstraction evolve for different communities of speakers. In addition, Brennan and Clark did not examine the use of names beyond the original director. Our results indicate that names are transmitted, not only to a conversational partner, but from that partner to others who were not part of the original interaction.
Our finding is also compatible with results of Markman and Makin (1998), who had pairs of people build complex LEGO models in order to study how communicative experience affects subsequent categorization. They noted that their dyads, who returned to the lab for a second session of model building between 2 and 5 days after the initial session, reused names they had created for the LEGO pieces in the first session. This observation indicates that names developed for an object in a dyadic interaction may persist as the preferred name between the members of the pair over a period of days. As in Garrod and Doherty (1994), however, their stimuli were complex, novel, abstract objects, and speakers generated complex multiphrase expressions to identify them initially; thus, the efficiency savings by reusing expressions agreed upon with a conversational partner may have been particularly high. In addition, Markman and Makin did not look at name use outside of the original dyad. We have shown that even simple nouns or modifier + noun names are carried forward in conversation from one partner to the next and beyond.

Our results thus provide a link between long- and shortterm historical influences on the choice of simple names for ordinary household objects. Conversational partners establish precedents for how to name objects. Each partner draws on the precedent when making subsequent reference to an object with the same partner, and each use of a name strengthens the association of that name to the object for the members of the pair. Such associations influence subsequent name retrieval and use both in conversation with the same partner and with others, and they influence conscious judgments of name preference as well. Our results indicate that such effects on naming endure well outside the time frame of working memory and beyond utterances that take place in immediate succession: They occurred in our experiments across multiple rounds of the matching task and following pauses as partners and roles in the game were switched. Markman and Makin's (1998) related results, in fact, demonstrate carryover effects in naming with time delays of up to 5 days. Thus, the sorts of effects we have shown here, which may be grounded in the same cognitive machinery as priming effects in memory, have the potential to carry forward across substantial time lags and in conversations with multiple partners, and ultimately to influence the naming pattern of an entire linguistic community.

In comparison with the strong effects of naming experience on name use and preference, judgments of the relation of the objects to standards associated with the name, in the form of typicality and similarity ratings, were more weakly influenced by the name manipulation. From one perspective, this outcome is contrary to what one might project: Although naming, similarity, and typicality can all be context-dependent, only naming is externally constrained by the previously established conventions of the linguistic community and the need to communicate with others who know those conventions. On this basis, naming might be expected to be relatively 
stable in the absence of shifts in goals or expertise of the audience or other aspects of context. However, our results indicate that naming is quite sensitive to past naming experiences, while typicality and similarity judgments are less so. This outcome is most likely due to differences in the importance of memory in the different processes: The name retrieved for an object on any occasion will be strongly influenced by episodes of associating the name to the object, whereas mental comparison of a specific object with a standard is less affected by past experience. This difference provides an explanation for how different populations of speakers may acquire different naming patterns within a domain while holding shared nonlinguistic understanding of the objects (Gennari, Sloman, Malt, \& Fitch, 2002; Malt et al., 1999).

Views of categorization as applied to the problem of object naming have focused almost exclusively on the role of the physical features and current function of the objects in naming choices, along with some attention to inferences about the object's intended use or origin. At the same time, the literature on referential communication tasks has shown clearly that name choices in any given situation with a particular conversational partner may be influenced by the goals of the task at hand and the mutual knowledge of speaker and addressee. Observations of naming patterns that differ across languages, as well as regionally within languages, demand explanations that go beyond either of these two avenues of investigation; they require explanations in terms of longer term influences on name choices. Recent research within the referential communication tradition has begun to provide insight into how short-term name selection may evolve into more enduring lexical preferences across a linguistic community. This recent work has focused primarily on cases where conversational partners are faced with unfamiliar tasks and complex, unfamiliar objects to which they must negotiate means of referring. Here, we have used a referential communication task to explore choices among existing familiar names at the same level of abstraction - names consisting of simple nouns or modifier + noun phrases-for common household objects, in order to begin to provide a link between shortand long-term influences on such choices.

\section{REFERENCES}

AshCRAFT, M. H. (1978). Property norms for typical and atypical items from 17 categories: A description and discussion. Memory \& Cognition, 6, 227-232.

BARR, D. J. (in press). The emergence of conventions in language communities. In J. C. Trueswell \& M. K. Tanenhaus (Eds.), World-situated language use: Psycholinguistic, linguistic, and computational perspectives on bridging the product and action traditions. Cambridge, MA: MIT Press.

BARR, D. J., \& KeYsar, B. (2002). Anchoring and comprehension in linguistic precedents. Journal of Memory \& Language, 46, 391-418.

Bloom, P. (1996). Intention, history, and artifact concepts. Cognition, 60, 1-29.

BRENNAN, S. E., \& Clark, H. H. (1996). Conceptual pacts and lexical choice in conversation. Journal of Experimental Psychology: Learning, Memory, \& Cognition, 22, 1482-1493.
Carmichael, L., Hogan, H. P., \& Walter, A. A. (1932). An experimental study of the effect of language on the reproduction of visually perceived form. Journal of Experimental Psychology, 15, 73-86.

Carroll, J. M. (1980). Naming and describing in social communication. Language \& Speech, 23, 309-322.

Clark, H. H. (1998). Communal lexicons. In K. Malmkjær \& J. Williams (Eds.), Context in language learning and language understanding (pp. 63-87). Cambridge: Cambridge University Press.

Clark, H. H., \& Marshall, C. R. (1981). Definite reference and mutual knowledge. In A. K. Joshi, B. L. Webber, \& I. A. Sag (Eds.), Elements of discourse understanding (pp. 10-46). Cambridge: Cambridge University Press.

Clark, H. H., \& Wilkes-Gibbs, D. (1986). Referring as a collaborative process. Cognition, 22, 1-39.

COHEN, J. (1988). Statistical power analysis for the behavioral sciences (2nd ed.). Hillsdale, NJ: Erlbaum.

GARrod, S., \& ANDERSON, A. (1987). Saying what you mean in dialog: A study in conceptual and semantic coordination. Cognition, 27, 181218

Garrod, S., \& Doherty, G. (1994). Conversation, coordination and convention: An empirical investigation of how groups establish linguistic conventions. Cognition, 53, 181-215.

Gennari, S. P., Sloman, S. A., Malt, B. C., \& Fitch, W. T. (2002) Motion events in language and cognition. Cognition, 83, 49-79.

Hock, H. H., \& JosePH, B. D. (1996). Language history, language change, and language relationship: An introduction to historical and comparative linguistics. Berlin: Mouton de Gruyter.

KeIL, F. C. (1989). Concepts, kinds, and cognitive development. Cambridge, MA: MIT Press.

Kemler Nelson, D. G. (1999). Attention to functional properties in toddlers' naming and problem-solving. Cognitive Development, $\mathbf{1 4}_{2}$ 77-100.

Krauss, R. M., \& Glucksberg, S. (1969). The development of communication: Competence as a function of age. Child Development, 40, 255-266.

KRAUSS, R. M., \& Weinheimer, S. (1966). Concurrent feedback, confirmation, and the encoding of referents in verbal communication. Journal of Personality \& Social Psychology, 4, 343-346.

LeVElt, W. J. M., \& Kelter, S. (1982). Surface form and memory in question answering. Cognitive Psychology, 14, 78-106.

LEWIS, D. (1969). Convention: A philosophical study. Cambridge, MA Harvard University Press.

Malt, B. C., Sloman, S. A., \& Gennari, S. (2003a). Speaking vs. thinking about objects and actions. In D. Gentner \& S. Goldin-Meadow (Eds.), Language in mind: Advances in the study of language and thought (pp. 81-111). Cambridge, MA: MIT Press.

Malt, B. C., Sloman, S. A., \& Gennari, S. (2003b). Universality and language specificity in object naming. Journal of Memory \& Language, 49, 20-42.

Malt, B. C., Sloman, S. A., Gennari, S., Shi, M., \& Wang, Y. (1999). Knowing versus naming: Similarity and the linguistic categorization of artifacts. Journal of Memory \& Language, 40, 230-262.

Malt, B. C., \& Smith, E. E. (1982). The role of familiarity in determining typicality. Memory \& Cognition, 10, 69-75.

Malt, B. C., \& Sмiтh, E. E. (1984). Correlated properties in natural categories. Journal of Verbal Learning \& Verbal Behavior, 23, 250-269.

MarkMAN, A. B., \& MAKIN, V. S. (1998). Referential communication and category acquisition. Journal of Experimental Psychology: General, 127, 331-354.

MetZing, C., \& BREnNan, S. E. (2003). When conceptual pacts are broken: Partner-specific effects on the comprehension of referring expressions. Journal of Memory \& Language, 49, 201-213.

Pickering, M. J., \& GARrod, S. (in press). Toward a mechanistic psychology of dialogue. Behavioral \& Brain Sciences.

RIPS, L. J. (1989). Similarity, typicality, and categorization. In S. Vosniadou \& A. Ortony (Eds.), Similarity and analogical reasoning (pp. 21-59). New York: Cambridge University Press.

Singleton, D. (2000). Language and the lexicon: An introduction. Oxford: Oxford University Press.

Sloman, S. A., Harrison, M. C., \& Malt, B. C. (2002). Recent exposure affects artifact naming. Memory \& Cognition, 30, 687-695. 


\section{NOTES}

1. The third director may have been aware that he or she was speaking to a matcher who had been the director in the first block. Thus, it might be suggested that this participant was carrying over terms from the experience with the second director only because he or she believed they were terms already used with this matcher. If the third director were making an explicit, motivated attempt to use the terms heard previously, however, it would be surprising to find only the obtained modest amount of carryover to the third block. Perhaps more important, in order for the third director to use terms that were originally used by the first one, the second director had to have passed those terms on to his or her matcher (the third director). In the second block, though, the director is speaking to a matcher who has not participated in a previous block, so under this explanation of the carryover, there is no reason that the prerequisite carryover in the second block would have occurred.

2. Brennan and Clark (1996; see also Metzing \& Brennan, 2003) assume that name agreement implies an agreement to conceptualize an object in a particular way. Pickering and Garrod (in press), giving a different type of account of coordination in dialogue, also assume that linguistic alignment leads to semantic and conceptual alignment. In situations such as those in Brennan and Clark's studies, where participants are looking at abstract shapes, choosing to call a particular ambiguous shape the ballerina rather than the skater may indeed have consequences for how the participants interpret details of the shape or encode it in memory (e.g., Carmichael, Hogan, \& Walter, 1932), although Brennan and Clark did not directly investigate those consequences. In our experiment, however, the stimuli were photos of actual household objects. The two alternative names used for each did not generally imply different properties, and to the extent that they might (e.g., trash can might tend to be associated with larger containers than wastebasket), a participant's understanding of the object properties is constrained by the properties displayed in the photo. In these cases, the notion of conversational partners forming a "conceptual" pact to think about the object as a "trash can" versus a "wastebasket" seems empty. In addition, our data indicate relatively little influence of the name coordination on similarity and typicality judgments, which reflect aspects of conceptualization. A more accurate way of talking about the observed phenomena within both our study and others' work is in terms of a naming agreement (or, to be entirely neutral about the mechanism of alignment, a naming precedent or coordination [Garrod \& Doherty, 1994]), with the possibility of conceptual consequences remaining open for exploration.

(Manuscript received August 11, 2003; revision accepted for publication March 8, 2004.) 